\title{
Grain refinement of primary silicon in hypereutectic Al-Si alloys by different P-containing compounds
}

\author{
Benson Kihono Njuguna', Jia-yan Li', Yi Tan', Qian-qian Sun', *Peng-ting Li ${ }^{1,2}$ \\ 1. School of Materials Science and Engineering, Dalian University of Technology, Dalian 116024, China \\ 2. State Key Laboratory of Advanced Special Steel, Shanghai University, Shanghai 200444, China \\ 3. Shandong Shanda Al\&Mg Melt Technology Company Limited, Jinan 250061, China
}

\begin{abstract}
The grain refinement behavior of Si-3P, Si-25Mn-10P, and Al-10Si-2Fe-3P master alloys on hypereutectic $\mathrm{Al}-24 \mathrm{Si}$ alloy was studied. Microstructure analysis indicates that the P-containing compounds in the three master alloys are SiP, MnP, and AIP, respectively. The coarse flower-like primary silicon in the Al-24Si alloy transforms into smaller, well-distributed blocks with the addition of various master alloys. When pouring at $840{ }^{\circ} \mathrm{C}$, the average grain size of the primary silicon refined by Si-25Mn-10P master alloy with a holding time of $30 \mathrm{~min}$ is about $18 \mu \mathrm{m}$, which is significantly smaller than those refined by Si-3P and Al-10Si-2Fe-3P master alloys. The grain size shows an increasing trend when the holding time is further prolonged. Higher holding temperature has a positive effect on the grain refinement of Si-25Mn-10P master alloy. The grain refinement mechanism of the three master alloys was also discussed.
\end{abstract}

Key words: grain refinement; primary silicon; master alloy; AIP compound

CLC numbers: TG146.21 Document code: A

Article ID: 1672-6421/2021 01-037-08

\section{Introduction}

Aluminum-based alloys are the most widely used engineering materials in the automotive and aeronautical industries due to their high strength-toweight ratio and high wear resistance ${ }^{[1-5]}$. Hypereutectic Al-Si alloys are particularly preferred as they exhibit a low coefficient of thermal expansion and a hightemperature strength ${ }^{[2-11]}$. These properties are attributed to the presence of the primary silicon phase in the aluminum matrix ${ }^{[7]}$. The castability of the alloy is also enhanced by the addition of silicon in the alloying process, by improving the melt flow ${ }^{[12]}$. However, the conventional casting procedures produce coarse grains of the primary silicon. These coarse grains are prone to premature crack initiation and fracture when subjected to tension loading ${ }^{[3,5,6,9]}$, which decrease the mechanical properties of the alloy ${ }^{[1]}$.

Many methods are used in the refinement and modification of the primary silicon phase to achieve optimum morphology for improving the mechanical

\section{*Peng-ting Li}

Male, Ph.D., Associate Professor. He is engaged in the research on microstructure modification and solidification control of Al-Si alloys and superalloys.

E-mail: ptli@dlut.edu.cn

Received: 2020-08-04; Accepted: 2020-12-10 properties of the alloys. These methods include electromagnetic stirring, rapid solidification, and the addition of minor elements ${ }^{[6,13,14]}$, among which, the addition of minor elements is the most common method, due to its simplicity and effectiveness ${ }^{[2,6,9]}$. P-based master alloys are efficient grain refiners for the primary silicon, and various P-based master alloys have been developed, such as Al-P, Al-Si-P, Al-Fe-P, SiMn-P, etc. ${ }^{[2,15]}$, which each have a different refinement process and effectiveness. However, studies concerning their different effects on nucleation abilities of primary silicon are rarely found.

In this study, hypereutectic $\mathrm{Al}-24 \mathrm{Si}$ (wt.\%, unless otherwise stated) alloys were refined by $\mathrm{Si}-3 \mathrm{P}, \mathrm{Si}-25 \mathrm{Mn}$ $10 \mathrm{P}$, and $\mathrm{Al}-10 \mathrm{Si}-2 \mathrm{Fe}-3 \mathrm{P}$ master alloys, respectively. The nucleation abilities of primary silicon with different P-containing compounds were studied, and the grain refining mechanism of the three master alloys was discussed. This work is beneficial to industrial applications of the P-based master alloys.

\section{Experiment procedure}

Commercial pure aluminum and silicon were used as raw materials to prepare the hypereutectic $\mathrm{Al}-24 \mathrm{Si}$ alloy in an electrical furnace using a graphite crucible. The $\mathrm{Si}-25 \mathrm{Mn}-10 \mathrm{P}$ and $\mathrm{Al}-10 \mathrm{Si}-2 \mathrm{Fe}-3 \mathrm{P}$ master alloys were provided by Shandong Al\&Mg Melt Tech Co., Ltd., 
and the Si-3P master alloy was prepared by vacuum induction melting method. At first, the prepared Al-24Si alloy was melted in an electrical resistance furnace at $810^{\circ} \mathrm{C}, 820^{\circ} \mathrm{C}$ and $840{ }^{\circ} \mathrm{C}$, respectively. After $20 \mathrm{~min}$ holding, the Si-3P, Si$25 \mathrm{Mn}-10 \mathrm{P}$ and $\mathrm{Al}-10 \mathrm{Si}-2 \mathrm{Fe}-3 \mathrm{P}$ master alloys were added into the melts, respectively, and stirred thoroughly. The addition amount of $\mathrm{P}$ is $350 \mathrm{ppmw}$ in these experiments. The melts were then poured into a pre-heated $\left(50{ }^{\circ} \mathrm{C}\right) \mathrm{KBI}$ cylindrical steel mold (50 $\mathrm{mm}$ in diameter and $25 \mathrm{~mm}$ in height) after further holding for 30,60 and $90 \mathrm{~min}$, respectively, to gain samples.

The samples for microstructure observation were cut from the center of the ingots. They were observed using an optical microscope (OM, LEICA DMi8), a scanning electron microscope (SEM, ZEISS SUPRA 55), and an electron probe microanalyzer (EPMA, JXA-8530F PLUS) with an energydispersive spectroscopy (EDS). The average grain size of the primary silicon was examined by ImageJ software. To determine the phosphorus content in the silicon phase in the refined samples, the particles were extracted by a special extraction method. Firstly, the Al matrix was dissolved in a solution of $10 \% \mathrm{HCl}$. Then, the particles in the solution were centrifuged by a centrifugal extractor, and then the collected sediments were rinsed with distilled water and ethanol for several times. Finally, the particles were analyzed using inductively coupled plasma atomic emission spectroscopy (ICP-AES, ICAP 7000 Plus).
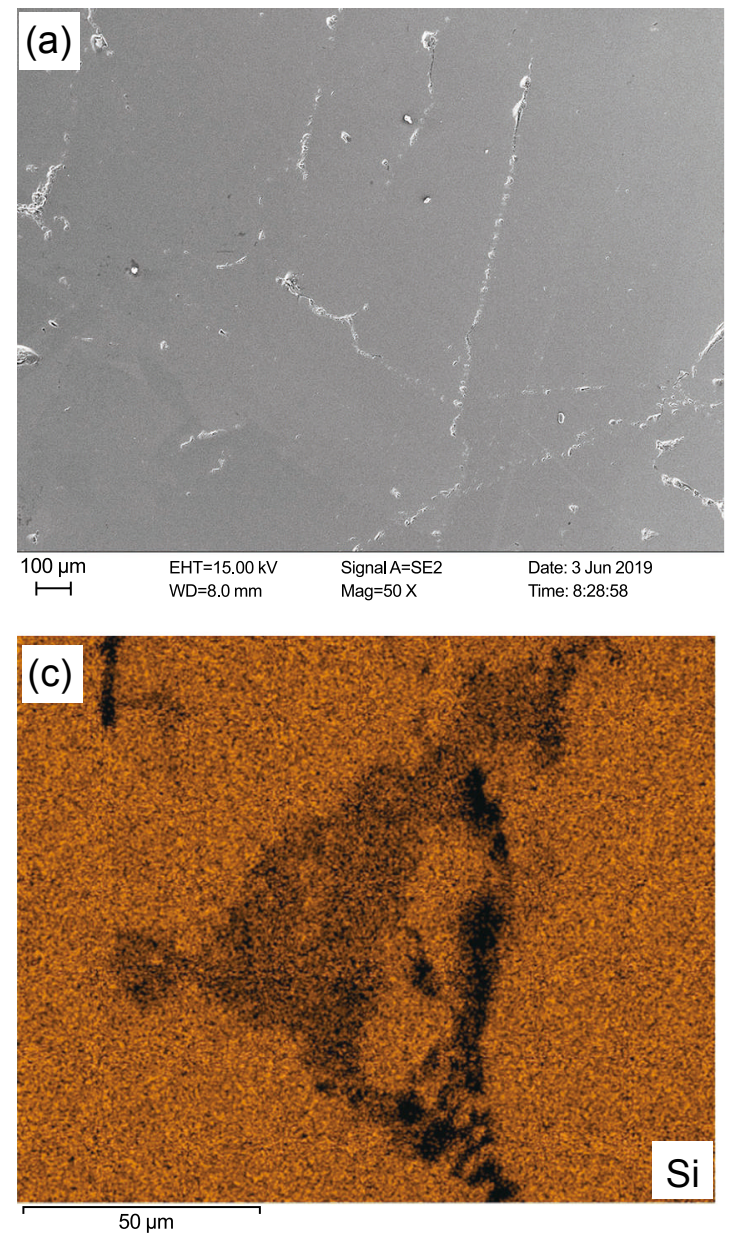

\section{Results and discussion}

\subsection{Microstructure of master alloys}

Different master alloys exhibit different microstructures and phase constitutions, which are responsible for the difference in refinement efficiency on Al-24Si alloy. Figure 1 shows the microstructure of the Si-3P master alloy. It can be seen that the Si-3P master alloy consists of two phases, the gray phase and the bright phase distributed at the grain boundary, as shown in Fig. 1(a). The EDS analysis result of the phase in the Si3P master alloy is shown in Fig. 2(b-d). It indicates that the gray phase is the Si matrix with trace phosphorus and the bright phase is the intermediate compound of SiP. According to research results by Sarafian et al. ${ }^{[16]}$, SiP intermediate compound appears in the Si-P alloy when the phosphorus content exceeds $1.0 \mathrm{wt} . \%$.

The microstructure of the Si-25Mn-P master alloy is shown in Fig. 2. The master alloy contains three phases. The dark phase is identified as the Si matrix with traces of Mn. By using the EDS analysis, the elemental composition of Phases A and B are listed in Table 1. It can be concluded that Phase A is MnP and Phase B in faint gray is $\mathrm{MnSi}_{x}$. From the SEM micrograph in Fig. 2(b), it can be seen that the MnP eutectic phase shows lamellar and labyrinth morphologies in the Si matrix.
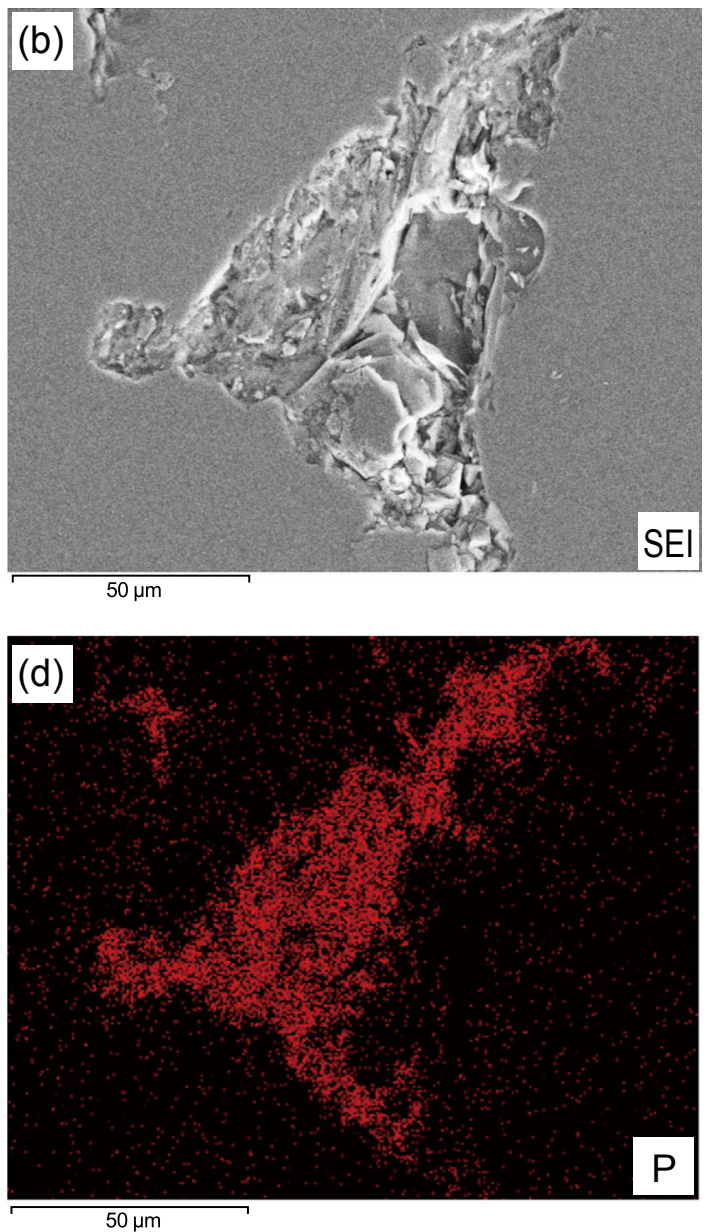

Fig. 1: Microstructures of Si-3P master alloy (a) and corresponding EDS result (b-d) 

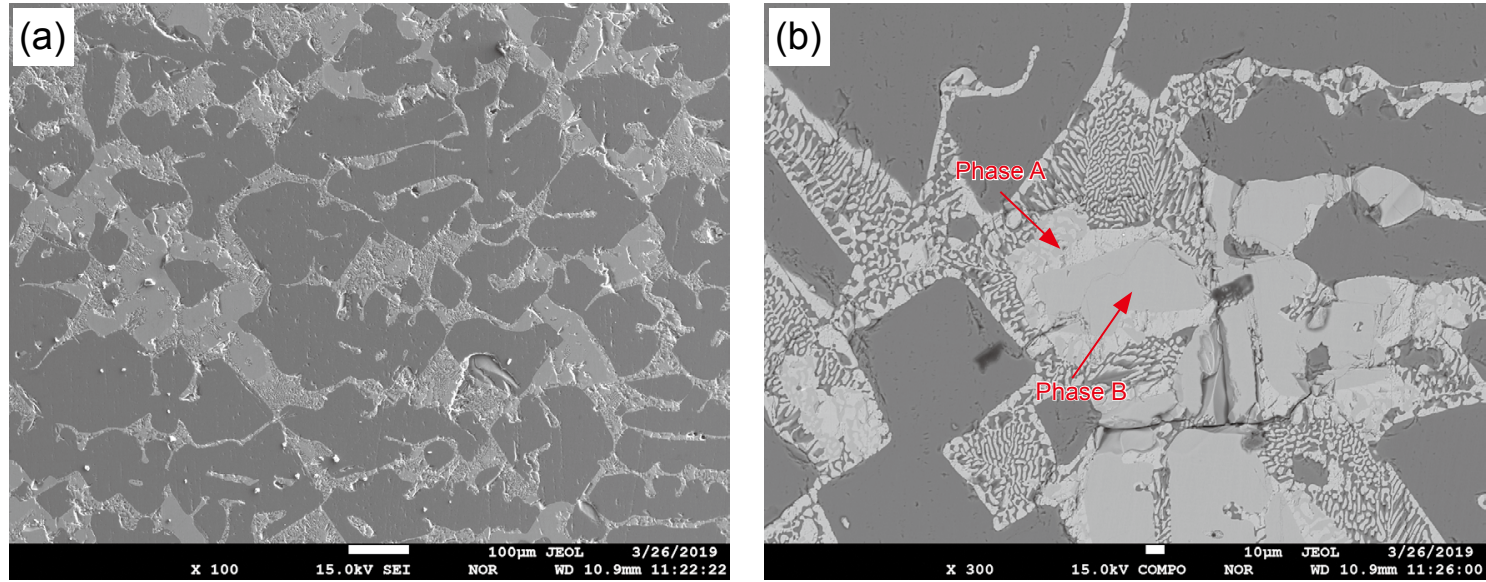

Fig. 2: Microstructures of Si-25Mn-10P master alloy: (a) low magnification; (b) high magnification

Table 1: Elemental composition of various phases in the Si-25Mn-10P master alloy

\begin{tabular}{ccccc} 
& \multicolumn{2}{c}{ Phase A } & \multicolumn{2}{c}{ Phase B } \\
Element & Mass (\%) & Atom (\%) & Mass (\%) & Atom (\%) \\
Si & 4.27 & 6.63 & 46.36 & 62.34 \\
$\mathrm{P}$ & 28.39 & 39.95 & 1.51 & 1.84 \\
$\mathrm{Mn}$ & 66.45 & 52.72 & 50.90 & 34.99 \\
$\mathrm{Fe}$ & 0.89 & 0.70 & 1.23 & 0.83 \\
Total & 100.00 & 100.00 & 100.00 & 100.00
\end{tabular}

Figure 3 shows the microstructure of the Al-10Si-2Fe-3P master alloy. A large number of phases are distributed on the Al matrix. From the XRD result of the master alloy shown in Fig. 4, it can be found the master alloy may contain $\mathrm{Si}$, AlP, AlFeSi phase and Al matrix. The elemental composition analysis of the various phases was carried out and the result is shown in Fig. 5. It can be concluded that the rod-like phase is eutectic Si and the needle-like phase is AlSiFe phase. As it is known, the AlP phase tends to hydrolyze during the sample preparation process ${ }^{[15]}$. As seen in the EDS images in Fig. 5, the element $\mathrm{O}$ is present in the same spot as element $\mathrm{P}$. AlP is unstable in air during sample preparation and reacts with water as follows:

$$
\mathrm{AlP}(\mathrm{s})+3 \mathrm{H}_{2} \mathrm{O}(\mathrm{g}) \rightarrow \mathrm{Al}(\mathrm{OH})_{3}(\mathrm{~s})+\mathrm{PH}_{3}(\mathrm{~g})
$$

Therefore, it is reasonable to believe that the bright phase is the hydrolyzed AlP particle, as shown in Fig. 3.

\subsection{Grain refinement performance of the three master alloys}

Figure 6 shows the microstructures of the Al-24Si alloy refined with $1.2 \%$ Si-3P at $840{ }^{\circ} \mathrm{C}$ and being held for different times.
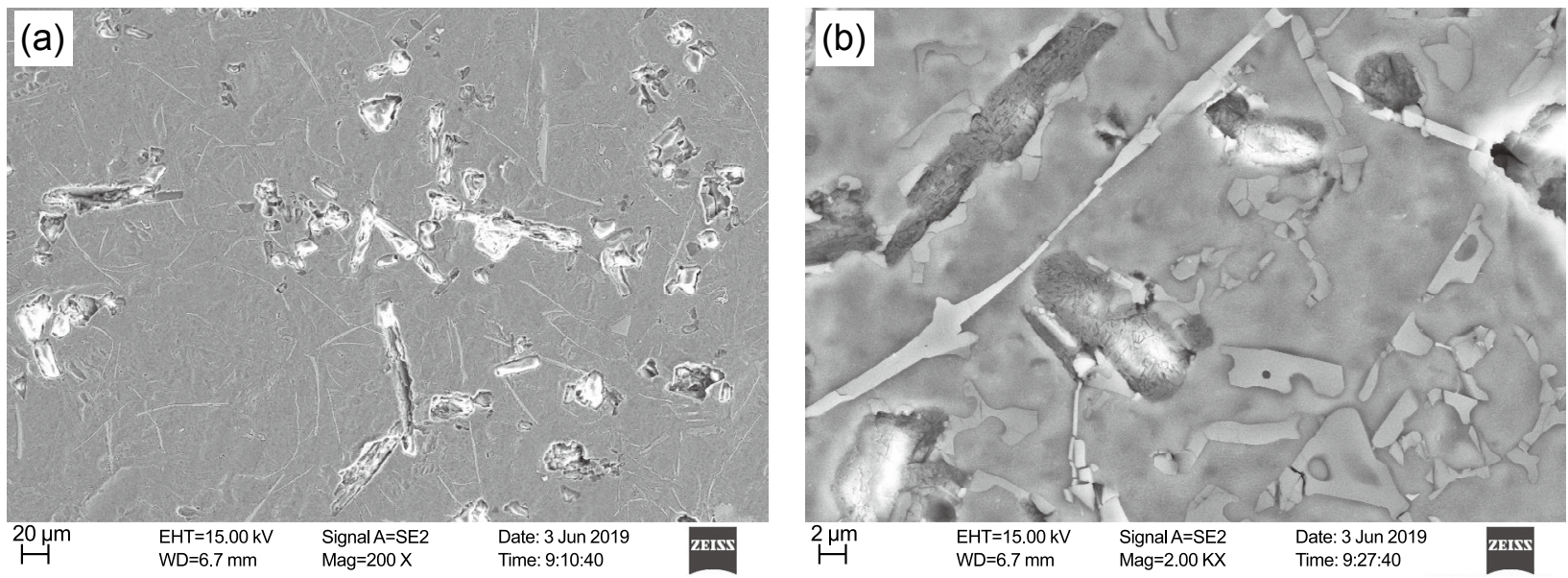

Fig. 3: Microstructures of Al-10Si-2Fe-3P master alloys: (a) low magnification; (b) high magnification 


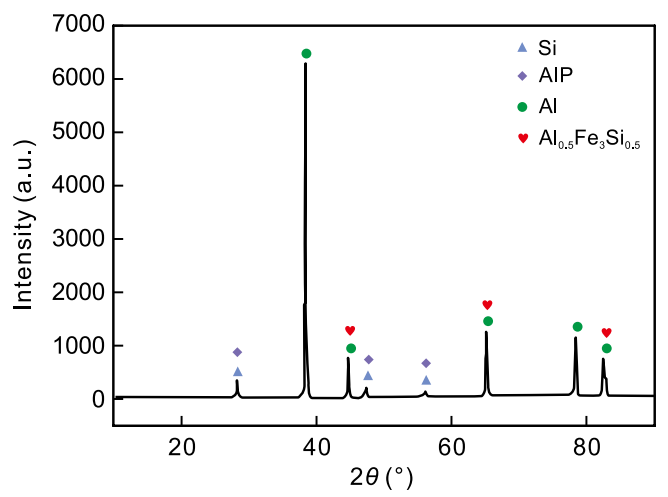

Fig. 4: XRD result of Al-10Si-2Fe-3P master alloy
The optical micrographs show a significant decrease in size and an improvement in shape of the primary silicon after refinement. The primary silicon without addition of grain refiner shows coarse five-petal or star-shaped flakes with a size of about $200 \mu \mathrm{m}$, as shown in Fig. 6(a). The best refinement results are obtained for the alloy with a holding time of $30 \mathrm{~min}$, as shown in Fig. 6(b). The grain size increases with a further increase in holding time, as shown in Figs. 6(c) and (d). Results by the ImageJ software shows that the average grain size of the primary silicon is $32 \mu \mathrm{m}$ with a holding time of $30 \mathrm{~min}$, and increases to about $42 \mu \mathrm{m}$ for $90 \mathrm{~min}$.
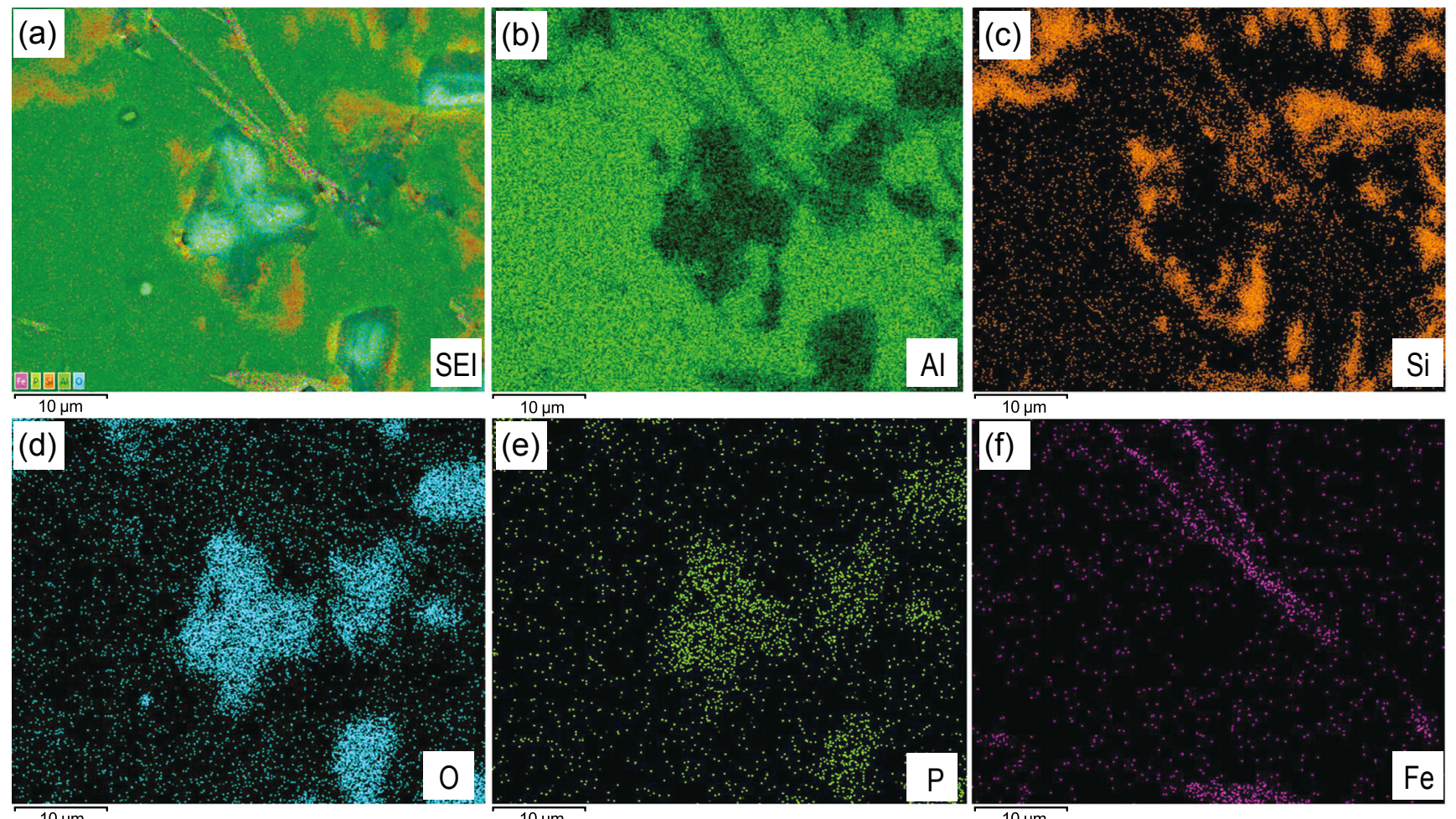

Fig. 5: EDS analysis of Al-10Si-2Fe-3P master alloy: (a) SEl image; (b) Al; (c) Si; (d) O; (e) P; (f) Fe

Figure 7 shows the microstructures of the Al-24Si alloy refined with $0.35 \% \mathrm{Si}-25 \mathrm{Mn}-10 \mathrm{P}$ master alloy at $840{ }^{\circ} \mathrm{C}$. It is obvious that the $\mathrm{Si}-25 \mathrm{Mn}-10 \mathrm{P}$ master alloy is successful in refining the primary silicon. The size and shape of the primary silicon exhibit a drastic change with the addition of the master alloy. Compared to the unrefined samples, the refined primary silicon changes to the blocky equiaxial shape after holding $30 \mathrm{~min}$ at $840{ }^{\circ} \mathrm{C}$, and the average grain size is about $18 \mu \mathrm{m}$. This grain refinement effect declines with the increase of the holding time, and the average grain size increases to about $28 \mu \mathrm{m}$ at $90 \mathrm{~min}$.

The grain refinement test of the Al-10Si-2Fe-3P master alloy on Al-24Si alloy was also carried out and the result is shown in Fig. 8. The best refinement effect is obtained for the alloy with a holding time of $30 \mathrm{~min}$, as shown in Fig. 8(b). The grain size increases with a further increase in holding time, as shown in Figs. 8(c) and (d). Results by the ImageJ software show that the average grain size of the primary silicon is $27 \mu \mathrm{m}$ with a holding time of $30 \mathrm{~min}$, and increases to about $34 \mu \mathrm{m}$ for $90 \mathrm{~min}$.

\subsection{Comparison of grain refinement performances}

Grain refinement performance comparison of the three master alloys is shown in Fig. 9. It can be seen that the Si-25Mn-10P master alloy exhibits the best grain refinement effect among the three master alloys. The primary silicon attains the grain size of less than $20 \mu \mathrm{m}$, which leads to a significant improvement in the mechanical properties ${ }^{[2,17]}$. Furthermore, the grain refinement effect of the three master alloys exhibits the best grain refinement effect with a holding time of $30 \mathrm{~min}$ and shows a deteriorating trend with prolonged holding time.

The effect of holding temperature on the grain refinement performance of the Si-25Mn-10P master alloy was carried out, as shown in Fig. 10. The result shows that the average grain size curves shift downwards as the refining temperature increases. It indicates the smallest grain size of the primary silicon is obtained at $840{ }^{\circ} \mathrm{C}$. This is consistent with the 

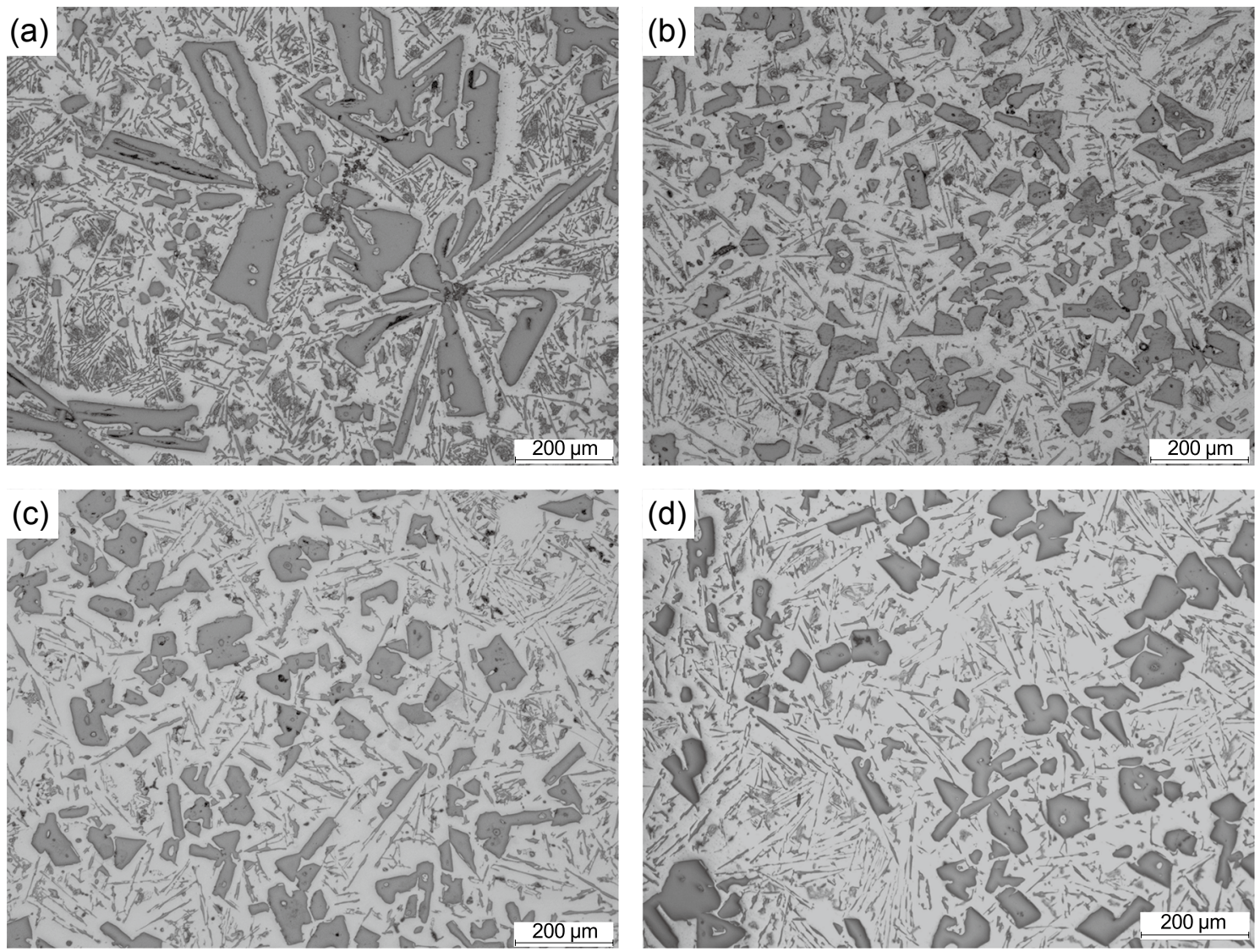

Fig. 6: Microstructures of unrefined (a) and refined (b-d) Al-24Si alloys with $1.2 \%$ Si-3P at $840{ }^{\circ} \mathrm{C}$ for different holding times: (b) $30 \mathrm{~min}$, (c) $60 \mathrm{~min}$, (d) $90 \mathrm{~min}$
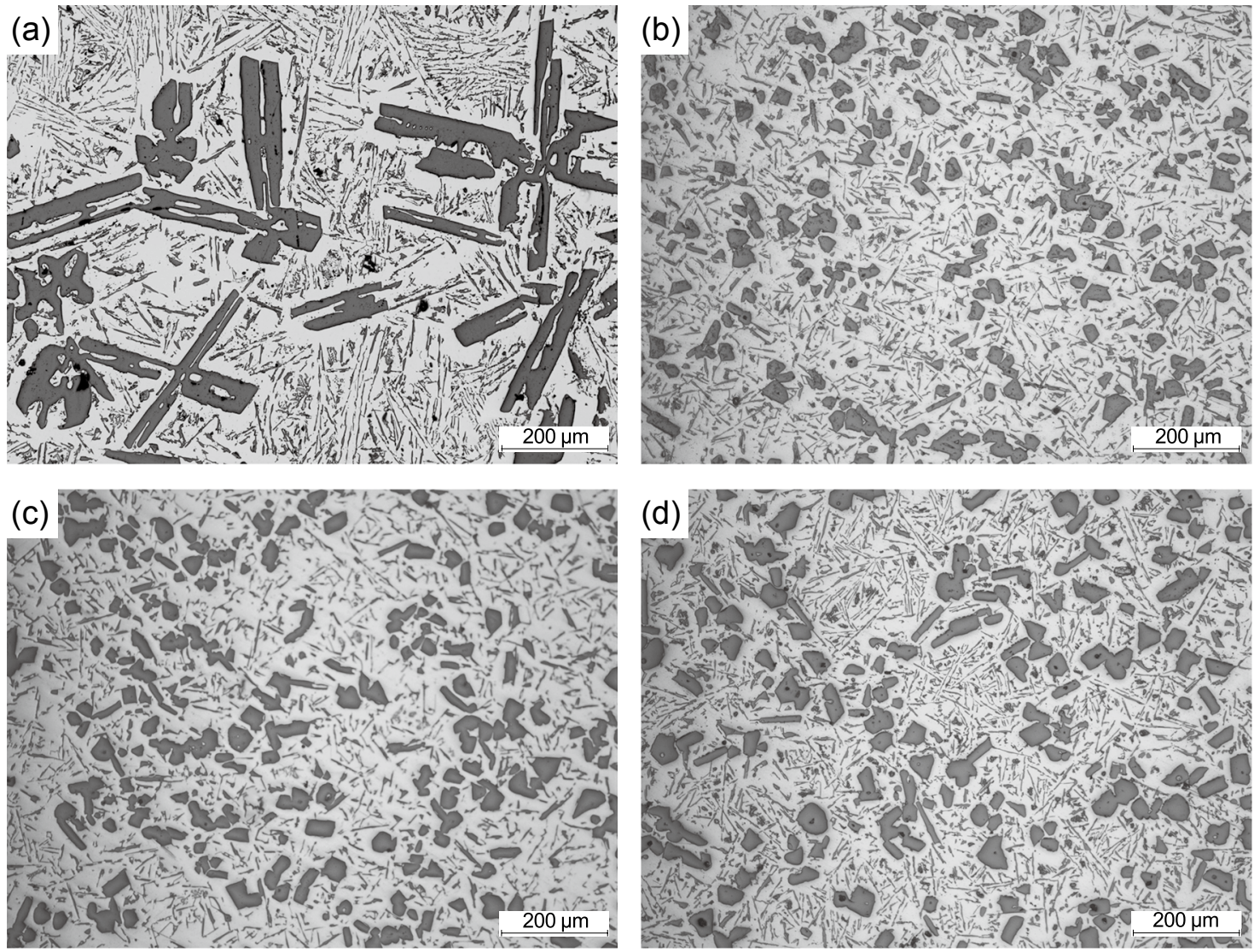

Fig. 7: Microstructures of unrefined (a) and refined (b-d) Al-24Si alloys with $0.35 \% \mathrm{Si}-25 \mathrm{Mn}-10 \mathrm{P}$ at $840{ }^{\circ} \mathrm{C}$ for different holding time: (b) $30 \mathrm{~min}$, (c) $60 \mathrm{~min}$, (d) $90 \mathrm{~min}$ 

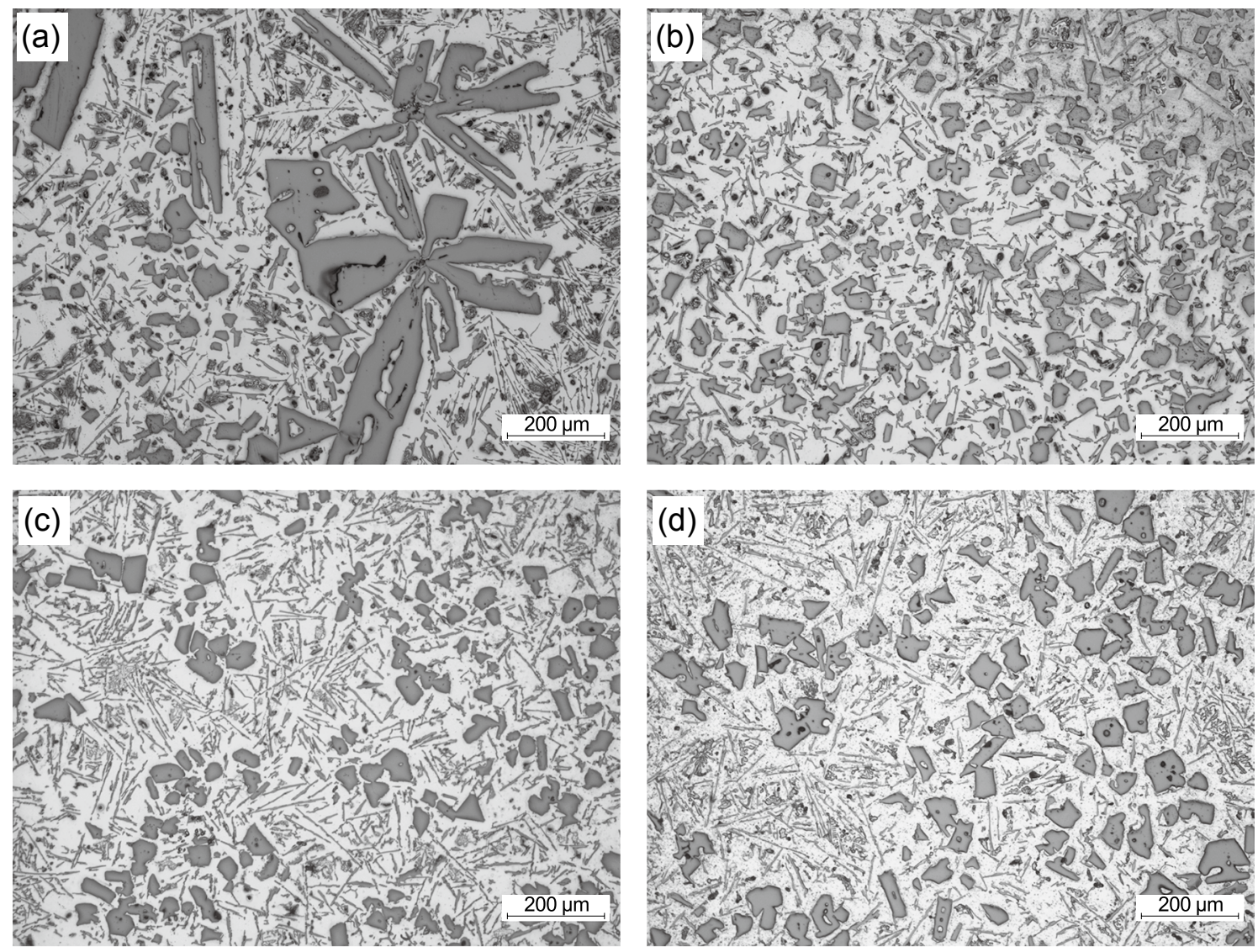

Fig. 8: Microstructures of unrefined (a) and refined (b-d) Al-24Si alloys with 1.2\% Al-10Si-2Fe-3P at $840^{\circ} \mathrm{C}$ : (b) $30 \mathrm{~min}$, (c) $60 \mathrm{~min}$, (d) $90 \mathrm{~min}$

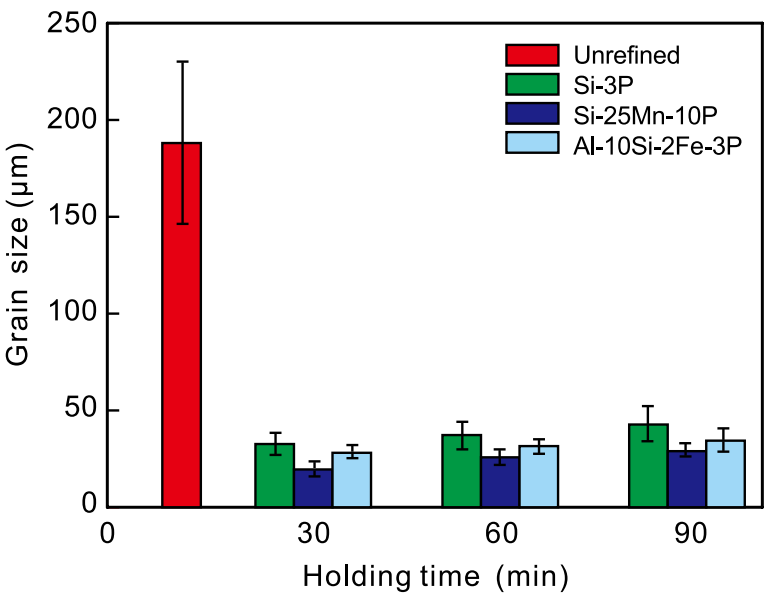

Fig. 9: Grain refinement performance comparison of the three master alloys

findings of $\mathrm{Wu}$ et al. ${ }^{[2]}$ that the effects of holding time are relatively lower than those of refining temperature. The effectiveness of a master alloy is affected mostly by the refining temperature and least affected by the holding time. This means that it is more effective to refine the primary silicon in hypereutectic $\mathrm{Al}-24 \mathrm{Si}$ alloy at $840{ }^{\circ} \mathrm{C}$ for just $30 \mathrm{~min}$ than using a lower temperature for a longer holding time.

To further elucidate the refinement process of the three master alloys, the Si phases in the Al-24Si alloys (including primary silicon and eutectic silicon) were extracted by hydrochloric acid.

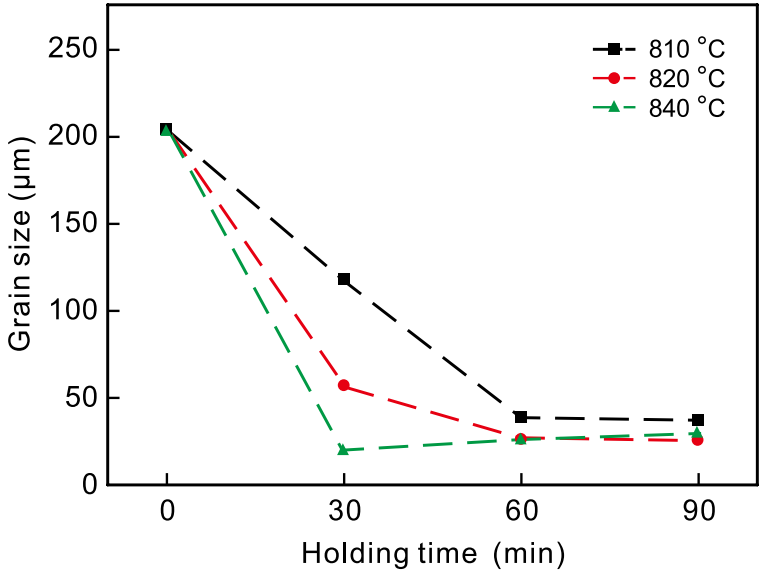

Fig. 10: Grain size variation of the primary silicon refined by $\mathrm{Si}-25 \mathrm{Mn}-10 \mathrm{P}$ master alloy with various holding temperatures

The phosphorus content in these Si phases for different samples was examined by the ICP-AES, and the results are shown in Table 2. From experimental data obtained in this experiment, the unrefined samples contain around 17.7 ppmw phosphorus element. In the samples refined by $\mathrm{Si}-25 \mathrm{Mn}-10 \mathrm{P}$ master alloy at $820^{\circ} \mathrm{C}$ and $840{ }^{\circ} \mathrm{C}$, the phosphorus content is $189.2 \mathrm{ppmw}$ and 385.9 ppmw, respectively. It can be seen that the refined samples exhibit significantly higher phosphorus content, which proves that the phosphorus content is closely related to the grain size of the primary silicon. 
Table 2: Phosphorus content in Si phase in Al-24Si alloys with different experiment processes

\begin{tabular}{|cc|}
\hline Sample & $\begin{array}{c}\text { Content } \\
(\text { ppmw })\end{array}$ \\
\hline $820^{\circ} \mathrm{C}$; No refiner & 17.7 \\
$820^{\circ} \mathrm{C} ; 0.35 \%$ Si-25Mn-10P refiner, holding $30 \mathrm{~min}$ & 189.2 \\
$840{ }^{\circ} \mathrm{C} ; 0.35 \%$ Si-25Mn-10P refiner, holding $60 \mathrm{~min}$ & 385.9
\end{tabular}

\section{Grain refinement mechanism of various P-containing compounds}

Many studies indicate that AlP phase has a lattice constant very similar to $\mathrm{Si}$, and therefore, has a good grain refining effect on the primary silicon ${ }^{[18-21]}$. From the phase constitution of the Al10Si-2Fe-3P master alloy in Fig. 4, it is clear that this master alloy has a pre-nucleated AlP phase. This is an important factor in the grain refinement efficiency of a P-based master alloy. The size of the AlP phase, however, must be within the allowable limits to act as inoculants ${ }^{[22]}$. The AlP phase needs to be dissociated to a much smaller size to act as seed for the primary silicon. The AlP phase with an undesirable form, such as a cluster or too large in size, hinders its efficiency in the refinement process. As a result, the Al-10Si-2Fe-3P master alloy does not show the best grain refinement performance in this work.

The Si-3P and Si-25Mn-10P master alloys follow a similar chemical process, whereby the master alloy is dissolved and releases $\mathrm{P}$-containing compounds into the melt. The $\mathrm{P}$-containing compounds then react with Al melt to form the AlP phase ${ }^{[10]}$. When the AlP phase is nucleated in the particulate form, it provides a large number of nucleation sites for the primary silicon. So, it can be concluded the effectiveness of the grain refiner is affected by the amount and the form of the AlP phase in the alloy melt ${ }^{[1]}$.

According to $\mathrm{Wu}$ et al. ${ }^{[2]}$, the Si matrix surrounding the SiP phase makes the Si-3P master alloy ineffective in grain refinement. This is because it is difficult for the Si-3P master alloy to dissolve into the melt due to the concentration gradient of $\mathrm{Si}$, as explained by Fick's law of diffusion. As a result, the Si-3P master alloy shows a poor grain refinement performance on the Al-24Si alloy. Additionally, even if the SiP phase is successfully dissolved into the melt, it is particularly difficult for it to react with $\mathrm{Al}$ melt at the normal refining temperatures.

The Si-25Mn-10P master alloy contained $\mathrm{Si}, \mathrm{MnP}$, and $\mathrm{MnSi}_{x}$ phases. It has no pre-nucleated AlP phase, because there is no $\mathrm{Al}$ as a constituent in the master alloy. So, the effectiveness of the Si-25Mn-10P master alloy cannot depend on the pre-nucleation of the AlP phase. This means that the MnP phase must be dissociated firstly and react with the Al melt to form the AlP phase. The reaction equation is shown as follows:

$$
\mathrm{MnP}(\mathrm{s})+\mathrm{Al}(\mathrm{l}) \rightarrow \mathrm{AlP}(\mathrm{s})+[\mathrm{Mn}]
$$

As said earlier, the Si-25Mn-10P master alloy has the MnP phase in the place of the SiP phase. The MnP has a smaller molecular weight compared to the SiP compound, making it faster in diffusion. Further, Wu et al. ${ }^{[2]}$ asserts that the SiP phase is extremely difficult to melt at the refining temperature. These factors explain why the Si-Mn-P master alloy gives better results in refining the primary silicon in hypereutectic Al-Si alloy. Additionally, the active compound, MnP, grows in the lamellar and labyrinth forms, as shown in Fig. 2. The lamellar and labyrinth form give the MnP compound more surface area for interaction, making it easier to break into $\mathrm{Mn}$ and $\mathrm{P}$. As a result, the Si-25Mn-10P master alloy shows better grain refinement performance than the other two master alloys.

\section{Conclusions}

(1) The P-containing compounds in Si-3P, Si-25Mn-10P, and Al-10Si-2Fe-3P master alloys are SiP, MnP, and AlP compounds, respectively. All the three master alloys are good grain refiners for the hypereutectic Al-Si alloy.

(2) When pouring at $840{ }^{\circ} \mathrm{C}$, the average grain size of the primary silicon refined by $\mathrm{Si}-25 \mathrm{Mn}-10 \mathrm{P}$ master alloy with a holding time of $30 \mathrm{~min}$ is about $18 \mu \mathrm{m}$, which is significantly better than those of the $\mathrm{Si}-3 \mathrm{P}$ and $\mathrm{Al}-10 \mathrm{Si}-2 \mathrm{Fe}-3 \mathrm{P}$ master alloys. The grain refinement of the master alloys shows a deteriorating trend with prolonged holding time.

(3) Higher holding temperature has a positive effect on the grain refinement of the $\mathrm{Si}-25 \mathrm{Mn}-10 \mathrm{P}$ master alloy.

\section{Acknowledgements}

The authors gratefully acknowledge the support of the National Natural Science Foundation of China (51974057 and 5174057), the Open Project of State Key Laboratory of Advanced Special Steel, Shanghai Key Laboratory of Advanced Ferrometallurgy, Shanghai University (SKLASS 2019-19) and the Science and Technology Commission of Shanghai Municipality (No. 19DZ2270200).

\section{References}

[1] Gong C J, Tu H, Wu C J, et al. Study on microstructure and mechanical properties of hypereutectic Al-18Si alloy modified with AI-3B. Materials, 2018, 11(3): 456. doi:10.3390/ ma11030456.

[2] Wu Y P, Wang S J, Li H, et al. A new technique to modify hypereutectic Al-24\%Si alloys by a Si-P master alloy, Journal of Alloys and Compounds, 2009, 477(1-2): 139-144. doi:10.1016/j.jallcom.2008.10.015.

[3] Wang K, Wei M, Zhang L J, et al. Morphologies of primary silicon in hypereutectic Al-Si alloys: phase-field simulation supported by key experiments. Metallurgical and Materials Transactions A, 2016, 47(4): 1510-1516. doi:10.1007/s11661016-3358-1.

[4] Singh R K, Telang A, Das S. Microstructure and mechanical properties of Al-Si alloy in as-cast and heat treated condition. American Journal of Engineering Research, 2016, 5(8): 133 137. 
[5] Biswas P, Patra S, Mondal M K. Effects of Mn addition on microstructure and hardness of Al-12.6Si alloy. IOP Conf. Series - Materials Science and Engineering, 2018, 338: 012043. doi:10.1088/1757-899X/338/1/012043.

[6] Gao T, Zhu X Z, Qiao H, et al. A new Al-Fe-P master alloy designed for application in low pressure casting and its refinement performance on primary $\mathrm{Si}$ in $\mathrm{A} 390$ alloy at low temperature. Journal of Alloys and Compounds, 2014, 607: 11-15. doi:10.1016/j.jallcom.2014.04.030.

[7] Meena P C, Sharma A, Singh S. Effect of grain refinement on microstructure and wear behavior of cast Al-7Si alloys. La Metallurgia Italiana, 2015, 107(1): 25-34.

[8] Marchwica P. Microstructural and thermal analysis of aluminum-silicon and magnesium-aluminum alloys subjected to high cooling rates. Dissertations: University of Windsor, 2012. http://scholar.uwindsor.ca/etd/5572.

[9] Xing P F, Gao B, Zhuang $Y X$, et al. On the modification of hypereutectic Al-Si alloys using rare earth Er. Acta Metallurgica Sinica, 2010, 23(5): 327-333. doi:10.1128/AEM.07790-11.

[10] Wu Y Y, Liu X F. Effect of $\mathrm{AlB}_{2}$ on the P-threshold in Al-Si alloy. Results in Physics, 2018, 9: 734-739. doi:10.1016/ j.rinp.2018.03.018.

[11] Jung J G, Lee $S$ H, Lee J M, et al. Improved mechanical properties of near-eutectic Al-Si piston alloy through ultrasonic melt treatmen. Materials Science and Engineering A, 2016, 669: 187-195. doi:10.1016/j.msea.2016.05.087.

[12] Qiu H X, Yan H, Hu Z. Modification of near-eutectic Al-Si alloys with rare earth element samarium. Journal of Materials Research, 2014, 29(11): 1270-1277. doi:10.1557/jmr.2014.113.

[13] Ho C R, Cantor B. Modification of hypoeutectic AI-Si alloys. Journal of Materials Science, 1995, 30: 1912-1920. doi:10.1007/BF00353013.

[14] Wang E Z, Liu S D, Nie J F, et al. A new kind of Al-5Ti-0.3C master alloy and its refining performance on 6063 alloys. Light Metals, 2015: 961-964. doi:10.1007/978-3-319-48248-4_161.
[15] Nie J F, Zhao Y H, Li Y S, et al. Reactive synthesis of hexagonal Ti5P3.16 crystals and their heterogenous nucleating mechanism on primary Si. Journal of Alloys and Compounds, 2019, 777: 8-17. doi:10.1016/j.jallcom.2018.09.038.

[16] Safarian J, Tangstad M. Phase diagram study of the Si-P system in Si-rich region. Journal of Materials Research, 2011, 26(12): 1494-1503. doi:10.1557/jmr.2011.130.

[17] Zhou X L, Zhu X Z, Gao T, et al. Evolution of a novel Si-18Mn16Ti-11P alloy in Al-Si melt and its influence on microstructure and properties of high-Si Al-Si alloy. Results in Physics, 2016, 6: 737-745. doi:10.1016/j.rinp.2016.10.006.

[18] Liang S M, Schmid-Fetzer R. Phosphorus in Al-Si cast alloys: Thermodynamic prediction of the AIP and eutectic (Si) solidification sequence validated by microstructure and nucleation undercooling data. Acta Materialia, 2014, 72: 4156. doi:10.1016/j.actamat.2014.02.042.

[19] Wu Y P, Wang S J, Li H, et al. A new technique to modify hypereutectic Al-24\% Si alloys by a Si-P master alloy. Journal of Alloys and Compounds, 2009, 477(1-2): 139-144. doi:10.1016/ j.jallcom.2008.10.015.

[20] Zhou X L, Wu Y Y, Li Y F, et al. Absorbing formation mechanism of AIP on $\mathrm{TiB}_{2}$ substrate and their application as high-efficiency nucleating agent in Al-45Si alloy. Journal of Alloys and Compounds, 2017, 693: 853-858.

[21] Li J H, Hage F S, Liu X F, et al. Revealing heterogeneous nucleation of primary $\mathrm{Si}$ and eutectic Si by AIP in hypereutectic Al-Si alloys. Scientific Reports, 2016, 6: 1-8.

[22] Jung J G, Ahn T Y, Cho Y H, et al. Synergistic effect of ultrasonic melt treatment and fast cooling on the refinement of primary $\mathrm{Si}$ in a hypereutectic Al-Si alloy. Acta Materialia, 2018, 144: 31-40. doi:10.1016/j.actamat.2017.10.039. 